\title{
Inhibiting PI3K reduces body weight in obese mice
}

Treating mice with CNIO-PI3Ki (an inhibitor of $\mathrm{PI} 3 \mathrm{~K}$ ) results in progressive weight loss, according to new research published in Cell Metabolism.

Diet-induced obese mice were treated with the inhibitor for 10 days, while being maintained on a high-fat diet. At the end of the treatment period, the mice had lost weight despite their food intake remaining constant. The most effective dosage (CNIO-PI3Ki at $15 \mathrm{mg} / \mathrm{kg}$ ) resulted in the treated mice achieving the same body weight as control mice on a standard diet within 10 days of initiating treatment. "In my opinion the response of the obese mice has features that I am not aware have been ever observed before with other antiobesity drugs," says corresponding author Manuel Serrano. Obese rhesus macaques treated with CNIO-PI3Ki for 3 months also showed reduced adiposity.

The researchers suggest that CNIOPI3Ki works by activating thermogenesis in brown adipocytes, which increases energy expenditure. Furthermore, mice fed a standard diet and given CNIOPI3Ki showed no change in body weight, suggesting that this inhibitor acts selectively in conditions of nutritional overload.

When treatment was discontinued, the mice regained the lost weight. "This finding indicates that the treatment does not produce irreversible metabolic changes," explains Serrano. The investigators did not observe any signs of toxicity with the treatment.

Serrano and colleagues hope to further clarify the mechanisms underlying the beneficial effects of inhibiting PI3K. They are also considering testing the compound in humans with obesity.

\section{Claire Greenhill}

Original article Ortega-Molina, A. et al. Pharmacological inhibition of PI3K reduces adiposity and metabolic syndrome in obese mice and rhesus monkeys. Cell Metab. doi:10.1016/j.cmet.2015.02.017 